\title{
A discursividade do sujeito sobre sentimentos associados ao enfrentamento da tuberculose*
}

\author{
The discourse of individuals on feelings associated with coping with tuberculosis
}

\author{
Discursividad del sujeto sobre sentimientos asociados al afrontamiento de la tuberculosis
}

Luana Carla Santana Oliveira ${ }^{1}$, Jordana de Almeida Nogueira ${ }^{2}$, Lenilde Duarte de Sá ${ }^{3}$, Pedro Fredemir Palha ${ }^{4}$, Cybelle Alves da Silva ${ }^{5}$, Tereza Cristina Scatena Villa ${ }^{6}$

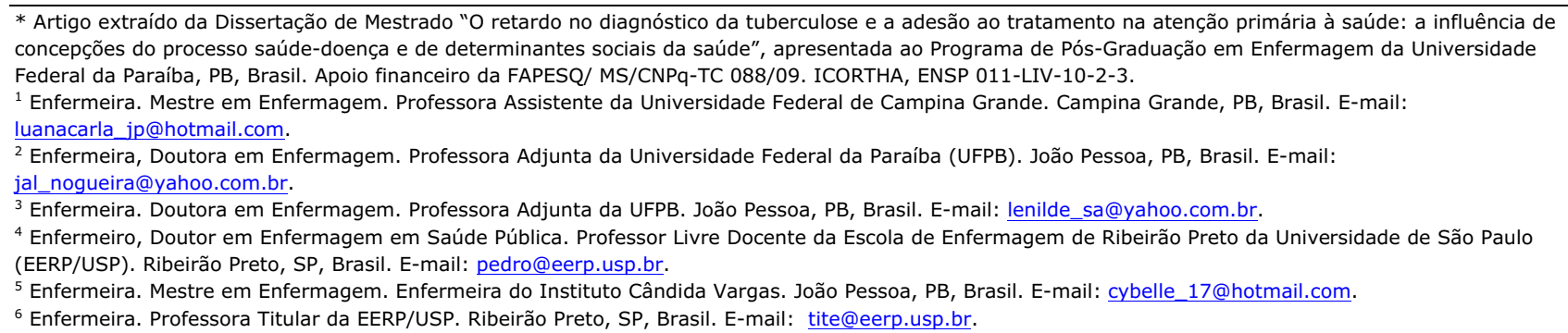

\section{RESUMO}

Objetivou-se compreender como os sentimentos do sujeito influenciam o enfrentamento da tuberculose. Estudo qualitativo realizado com nove indivíduos em tratamento de tuberculose, residentes em município portuário do Brasil. Na produção do material empírico, utilizouse a técnica de entrevista semiestruturada e, como referencial teórico-analítico, a análise de discurso de matriz francesa. Os resultados mostraram que aspectos culturais e sociais influenciaram o enfrentamento da doença e determinaram a busca por cuidados e a adesão terapêutica. A automedicação, o estigma, o sentimento de medo frente à gravidade da doença, a deficiência dos profissionais para suspeição e diagnóstico contribuíram para a busca tardia do serviço de saúde. O tratamento prolongado, a ocorrência de reações adversas e a percepção precoce de cura fragilizaram a adesão ao tratamento. Reconhecer que a busca por cuidados varia segundo as singularidades dos sujeitos, confere direcionalidade à formulação de estratégias eficazes e de mudanças nas ações de controle da tuberculose.

Descritores: Tuberculose; Atenção Primária à Saúde; Emoções; Diagnóstico Tardio; Adesão à Medicação.

\section{ABSTRACT}

The objective of this study was to understand how a subject's feelings influence coping with tuberculosis. A qualitative study was developed with nine individuals undergoing tuberculosis treatment, living in a port city in Brazil. Semi-structured interviews were used in the empirical material production, and the French discourse analysis was used as theoretical-analytical framework. Results showed that cultural and social aspects influenced coping with the disease and determined the search for care and the therapeutic compliance. Selfmedication, stigma, the feeling of fear in face of the critical nature of the disease, and the deficiency of professionals for suspicion and diagnosis contributed for users to search for health services late. The prolonged treatment, incidence of adverse reactions and early perception of cure hampered compliance with the treatment. Recognizing that the search for care varies according to the subjects' singularities directs the formulation of effective strategies and changes in tuberculosis control actions.

Descriptors: Tuberculosis; Primary Health Care; Emotions; Delayed Diagnosis; Medication Adherence.

\section{RESUMEN}

Se objetivó comprender la influencia de los sentimientos del sujeto sobre el afrontamiento de la tuberculosis. Estudio cualitativo realizado sobre nueve individuos en tratamiento de tuberculosis, residentes en municipio portuario brasileño. Se aplicó entrevista semiestructurada en la producción del material empírico, apelándose al referencial teórico del análisis del discurso de matriz francesa. Los resultados mostraron que los aspectos socioculturales influyeron en el enfrentamiento de la enfermedad y determinaron la búsqueda de cuidados y adhesión terapéutica. La automedicación, el estigma, el sentimiento de miedo por la gravedad de la enfermedad, las carencias de los profesionales para detección y diagnóstico, contribuyeron a búsquedas tardías de servicios de salud. El tratamiento prolongado, aparición de reacciones adversas y percepción de cura precoz fragilizaron la adhesión al tratamiento. Reconocer que la búsqueda de cuidados varía según las particularidades individuales orientan la formulación de estrategias eficaces y de cambio de acciones de control de la tuberculosis.

Descriptores: Tuberculosis; Atención Primaria de Salud; Emociones; Diagnóstico Tardío; Cumplimiento de la Medicación. 


\section{INTRODUÇÃO}

A tuberculose (TB), apesar dos avanços e incentivos, como a estratégia DOTS (Directly Observed Treatment Short-Course) e a terapêutica medicamentosa eficaz e acessível, representa aditivo significativo de sofrimento e grande obstáculo para o desenvolvimento socioeconômico no mundo ${ }^{(1)}$. Em 2012, a Organização Mundial de Saúde (OMS) estimou a existência de 8,6 milhões de casos novos da doença e 1,4 milhão de óbitos. O Brasil ocupa o $19^{\circ}$ lugar entre os 22 países com a mais alta carga de TB notificada no mundo e concentra $35 \%$ dos casos notificados na região das Américas. Em 2012, foram notificados no país, 70.047 casos novos da doença, correspondendo a um coeficiente de incidência de $36,1 / 100.000$ habitantes. Anualmente, morrem cerca de 4,5 mil pessoas por TB, sendo a quarta causa de morte por doenças infecciosas e a primeira causa de morte dos pacientes com AIDS (Acquired Immune Deficiency Syndrome) $)^{(2)}$.

Logo, a compreensão dos fatores que condicionam a permanência da TB no ranking dos agravos transmissíveis requer uma avaliação integral da realidade e consequente implementação de medidas eficazes de controle da doença.

O retardo do diagnóstico da TB e a não adesão ao tratamento constituem-se barreiras para o controle da enfermidade, pois implicam em um mau prognóstico e na maior disseminação da doença. O atraso do diagnóstico tem sido definido como o intervalo de tempo entre o aparecimento dos sintomas e o início do tratamento e pode estar relacionado às características do sujeito (contexto socioeconômico do indivíduo e da família, fatores étnicos/raciais e culturais, percepções do processo saúde-doença, questões comportamentais e religiosas, severidade dos sinais e sintomas) e dos serviços de saúde (dificuldade de acesso, inadequado acolhimento do usuário, baixa prioridade na procura de sintomáticos respiratórios e de contatos intra-domiciliares, baixo nível de suspeição diagnóstica) $)^{(3-4)}$.

Com relação aos aspectos culturais, psicológicos e comportamentais, ressalta-se que as pessoas acometidas por TB são seres clivados de sentimentos que constroem significados da saúde, desvelados no interdiscurso, nas relações, na intersubjetividade. Estes sentimentos, mediante interpretação, geram sentidos, os quais traduzem o modo como enfrentam a doença por si mesmo, impelem a busca de um cuidado oficial e influenciam a maneira de enfrentar o tratamento ${ }^{(5)}$.

A apreensão dos fatores que influenciam o retardo do diagnóstico e a adesão ao tratamento na perspectiva dos portadores de TB, extrapola conceitos e técnicas e reitera a necessidade de reconhecer que cada sujeito tem um modo singular de compreender e enfrentar a doença. Punição ou castigo; incapacidade ou dependência; ausência de saúde; desequilíbrio; impotência funcional, indisposição ou apatia; práticas insalubres; alteração do ritmo de vida; condições financeiras precárias; não estar bem consigo, com o outro e com o mundo; e a presença de agentes agressores externos e/ou internos são possibilidades de expressão populares que fornecem um leque de significados, auxiliando-nos quanto à percepção do indivíduo doente ${ }^{(6)}$.

Os diversos conceitos atribuídos à saúde estão intrínsecos aos valores individuais e às concepções científicas, religiosas, filosóficas e culturais $^{(7)}$. A cada experiência, o homem cria e recria significados e símbolos do seu processo saúde-doença, das formas de prevenção, de tratamento e cura. Para compreender os fatores que causam mudanças de comportamentos e de práticas, é necessário discorrer sobre o significado de comportamentos, os quais expressam percepções, valores, representações simbólicas, relações de poder, crenças e sentimentos. Deste modo, é recomendável considerar a subjetividade inerente aos sujeitos e as representações do processo saúde-doença ${ }^{(8)}$.

Nesta perspectiva, na atenção à TB, é imprescindível a mudança do modelo tradicional ainda vigente, centralizado na doença, para um modelo dialógico que reconheça o sujeito com suas concepções e saberes, o que não pode ser deslegitimado pelos serviços. Portanto, fazse necessária a adoção de medidas que transcendam ao corpo biológico e apontem em direção às transformações de valores, ideologias e concepções da sociedade ${ }^{(9)}$.

Desta forma, considerando a interpretação do adoecer por TB, o retardo do diagnóstico e a busca por alternativas complementares do cuidado como fatores que influenciam a adesão ao tratamento oficial, entendemos ser relevante compreender como os sentimentos do sujeito influenciam o enfrentamento da doença, sendo este o objetivo deste estudo. Ressalta-se que não pretendemos saturar a análise destas questões, mas perscrutar a discursividade dos sujeitos com TB, na ânsia de contribuir para construção de conhecimentos que diminuam o adoecimento de outros e demais desfechos que não sejam a cura, através de mudanças nas práticas de saúde direcionadas aos usuários com TB. 


\section{MÉTODO}

Trata-se de uma pesquisa descritiva, de abordagem qualitativa, realizada em Cabedelo, município portuário da região metropolitana de João Pessoa-PB, o qual se destaca epidemiologicamente pela alta incidência de casos de TB.

Para estabelecer o grupo de participantes do estudo, inicialmente foi traçado um breve perfil epidemiológico da doença naquela cidade. Em 2012, foram registrados no município, 31 casos novos da doença, com uma taxa de incidência de 46,59 /100.000 habitantes, superior ao coeficiente nacional ${ }^{(10)}$. No período do estudo, foram identificados pelo Sistema de Informação de Agravos de Notificação, dezoito casos de tuberculose em tratamento. A partir desse número de casos, estabelecemos o grupo de participantes da pesquisa. Foram excluídos os casos em situação de abandono do tratamento, menores de dezoito anos, residentes em áreas de extremo risco de violência e institucionalizados (em internação hospitalar e reclusos em presídios). Com base nestes critérios, determinou-se a participação de nove sujeitos.

Como instrumento para produção do material empírico, elegeu-se a técnica de entrevista semiestruturada, baseada em um roteiro que incluiu a caracterização social dos entrevistados (sexo, idade, escolaridade, religião, ocupação, estilo de vida tabagismo e etilismo) e questões referentes ao retardo do diagnóstico e à adesão ao tratamento, considerando atributos dos sujeitos com TB (concepções do processo saúde-doença e do adoecer por TB, prática da automedicação, vivência do estigma, atitudes de abandono, dentre outros) e características relacionados aos serviços de saúde (barreiras de acesso, resolutividade do serviço de saúde oficial, percurso do usuário até o diagnóstico da doença).

As entrevistas foram previamente agendadas e realizadas nos domicílios, em locais que garantiram privacidade aos sujeitos para responderem às nossas questões de investigação, ocorridas entre os meses de agosto e outubro de 2011. As entrevistas foram gravadas após aquiescência dos entrevistados para, posteriormente, serem transcritas.

O referencial teórico-analítico utilizado no processo de análise do material empírico foi a Análise de Discurso $(A D)$, de matriz francesa, que trata da determinação histórica dos processos de significação, considerando como foco central a relação entre a linguagem e seu contexto de produção. Além do exposto, esta teoria revela que não há discurso sem sujeito e nem sujeito sem ideologia, sendo a linguagem um espaço social de debate e de conflito ${ }^{(11)}$.
Para realizar a análise na perspectiva da $A D$, foram consideradas três etapas: a primeira caracterizou-se pela constituição do corpus, definindo seus limites, fazendo recortes e iniciando o trabalho de análise a partir da retomada de conceitos em um ir-e-vir constante entre teoria, consulta ao corpus e análise, transformando a superfície linguística no objeto discursivo. A segunda etapa constituiu-se pela passagem do objeto discursivo para o processo discursivo, a partir da observação dos sentidos do texto, identificando-se as sequências e os fragmentos discursivos. Estes sentidos são determinados ideologicamente, não se expressando na essência das palavras, mas na discursividade dos sujeitos ${ }^{(5)}$. Na terceira etapa, procedeu-se o agrupamento dos fragmentos discursivos, dos quais emergiram três formações discursivas (FD): "A relação dos sentimentos dos sujeitos com o adoecimento por TB e as estratégias de enfrentamento utilizadas"; "A busca pelo serviço de saúde oficial mediada pelo agravamento da sintomatologia"; "Os sentimentos dos sujeitos frente ao tratamento e a busca de cuidados complementares".

O projeto da pesquisa foi submetido à apreciação do Comitê de Ética em Pesquisa do Centro de Ciências da Saúde da Universidade Federal da Paraíba - UFPB, atendendo às orientações inerentes ao protocolo de pesquisa contido na Resolução CNS 466/2012, sendo aprovado em 17 de dezembro de 2008, sob o no. 0589. Cada entrevistado participou da pesquisa mediante a aceitação e a assinatura do Termo de Consentimento Livre e Esclarecido, sendo garantido o sigilo das informações. Com o objetivo de garantir o anonimato dos sujeitos da pesquisa, os entrevistados foram denominados de E-1, E2 até E-9, conforme sequência de realização das entrevistas.

\section{RESULTADOS E DISCUSSÃO}

O conhecimento do "modo de andar a vida" dos sujeitos com TB permite compreender como as condições de vida geram sentidos e interpretações na descoberta e no enfrentamento da doença. Desta forma, foram traçadas considerações sobre o contexto social dos participantes da pesquisa, corroborando a concepção de que as iniquidades sociais da saúde influenciam a forma do sujeito lidar com a doença. O município onde residem os sujeitos entrevistados possui alta densidade populacional de $1.815,57$ hab./ $\mathrm{km}^{2}$, uma incidência de pobreza de $54,8 \%$, ocupa o 20 lugar no ranking do Índice de Desenvolvimento Humano Municipal - IDHM do estado da Paraíba, Brasil, com 0,757, apresenta uma taxa de analfabetismo de 10,7\% (no Brasil esta taxa corresponde 
a 9,6\%) e apenas $51 \%$ dos domicílios têm saneamento básico adequado (no Brasil corresponde a $61,8 \%)^{(12)}$.

Todos os participantes moram em bairros periféricos, sendo que cinco deles residem em moradias precárias e de risco. Os entrevistados têm acesso à água tratada e à energia elétrica, mas o destino dos dejetos não é adequado. Todos dispõem de serviços de saúde acessíveis, com unidade de saúde da família próxima às residências, um hospital geral do município, além de serviços ambulatoriais e ainda podem ser encaminhados ao hospital de referência em João Pessoa (município limite e pertencente à mesma região metropolitana).

A vinculação entre pobreza e TB está relacionada aos indicadores de status socioeconômicos como aglomerados anormais, pobreza, desemprego e situações habitacionais superlotadas e insalubres, concorrendo para a disseminação da TB na comunidade e o consequente aumento da incidência da doença. Além disso, o acesso reduzido aos serviços de saúde, também reflexo da pobreza, pode acarretar a demora do diagnóstico e do tratamento $^{(1,13)}$.

A maioria dos entrevistados apresenta baixa escolaridade (até seis anos de estudo), o que revela o baixo desenvolvimento socioeconômico destes sujeitos e se constitui uma barreira no acesso às informações sobre TB. Uma pesquisa na Etiópia acerca do diagnóstico da TB identificou que os doentes com mais de oito anos de estudo estavam menos propensos ao retardo do diagnóstico ${ }^{(4)}$. Observa-se também que a maioria dos entrevistados trabalha no mercado informal ou está desempregada; apenas dois sujeitos trabalhavam formalmente. Um estudo realizado na China identificou que as barreiras econômicas em termos de nível baixo de renda, foi um fator que influenciou o comportamento de busca dos indivíduos e a demora do diagnóstico da $\mathrm{TB}^{(13)}$.

Em relação ao estilo de vida dos participantes da pesquisa, do total de nove, cinco relataram tabagismo por mais de dez anos, seis referiram serem etilistas e dois afirmaram o uso de drogas ilícitas. Ressalta-se a associação destes comportamentos com a dificuldade de adesão ao tratamento.

Os sujeitos entrevistados foram questionados sobre suas concepções e sentimentos relacionados ao processo de adoecimento por TB, sendo composta a Formação Discursiva I, com seus fragmentos discursivos apresentados nos Quadros 1 e 2 .

Quadro 1: Sentimentos dos usuários desencadeados pela confirmação diagnóstica da TB. Cabedelo, PB, Brasil, 2011.

\begin{tabular}{|c|c|}
\hline $\begin{array}{l}\text { Sequências } \\
\text { discursivas }\end{array}$ & Fragmentos Discursivos \\
\hline $\begin{array}{l}\text {...usuário tem medo da } \\
\text { morte }\end{array}$ & $\begin{array}{l}\text { [...] Pensei que eu ia morrer. Eu tenho muito medo de morrer, mas não é por nada, é de deixar } \\
\text { meus filhos. [choro longo] [...] (E-5). }\end{array}$ \\
\hline $\begin{array}{l}\text { Medo da morte; } \\
\text { tranquilidade ao saber } \\
\text { que a doença tinha cura }\end{array}$ & $\begin{array}{c}\text { Eu fiquei chorando, chorei bastante. [...] Pensei que podia ir ao óbito, que eu poderia até } \\
\text { morrer, perder algum órgão do meu corpo, um pulmão, um fígado qualquer coisa assim. Eu vi } \\
\text { passar na televisão que a tuberculose tem cura, aí eu fiquei mais tranquilo em relação a minha } \\
\text { melhora }(E-6) .\end{array}$ \\
\hline Possível ideia de suicídio & Pensei muitas coisas... Fazer besteira... (E-7). \\
\hline $\begin{array}{l}\text { Vergonha e rejeição } \\
\text { social, ideia de desprezo } \\
\text { e de ausência de saúde }\end{array}$ & $\begin{array}{l}\text { [...] Eu fiquei com medo, fiquei triste, nunca tinha acontecido isso comigo, porque eu achava } \\
\text { que era uma doença feia, que pegava, eu achava que não tinha cura. [...] Eu senti vergonha de } \\
\text { dizer que eu estava com tuberculose, não digo a ninguém não [...] A gente quando tem uma } \\
\text { doença assim, a gente se sente rejeitada por todo mundo. Eu sentia muito desgosto da minha } \\
\underline{\text { vida. [choro] (E-4). }}\end{array}$ \\
\hline \multirow[b]{2}{*}{$\begin{array}{l}\text { Ideia de desprezo e de } \\
\text { não ter mais saúde }\end{array}$} & $\begin{array}{c}\text { Que eu ia ser desprezada pela minha família. Senti que eu não ia ter mais saúde com esse } \\
\text { problema }[\ldots](E-7) .\end{array}$ \\
\hline & $\begin{array}{l}\text { Eu me sinto desprezado. Eu moro sozinho e essa doença eu não gosto nem de dizer essa } \\
\text { palavra. Meu pai já morreu de tuberculose. Sinto vergonha. Meu irmão também já teve. [...] Eu } \\
\text { sou difícil de procurar ajuda, eu não gosto não. Eu não gosto de ir ao médico, de ir ao hospital. } \\
\text { Vai fazer um ano e três meses que eu moro aqui e se você chegar no posto ali você não é bem } \\
\text { recebido, eu sinto raiva. No posto aí devido a essa minha doença já saíram falando (E-8). }\end{array}$ \\
\hline \multirow{2}{*}{$\begin{array}{c}\text { Ausência de } \\
\text { sentimentos negativos } \\
\text { ao saber que a doença } \\
\text { tem cura }\end{array}$} & $\begin{array}{c}\text { Eu não senti muita coisa não, porque sempre ouvia falar que tinha cura, disseram que era só } \\
\text { fazer o tratamento que tinha cura }(E-3) .\end{array}$ \\
\hline & Fiquei normal. Porque falaram que tem cura $(E-1)$. \\
\hline
\end{tabular}


Quadro 2: A prática da automedicação como primeira estratégia de cuidado no estágio inicial da doença. Cabedelo, PB, 2011.

\begin{tabular}{|c|c|}
\hline Sequências discursivas & Fragmentos Discursivos \\
\hline \multirow{4}{*}{$\begin{array}{l}\text { Automedicação: Usos de substâncias } \\
\text { alopáticas e medicamentos caseiros }\end{array}$} & $\begin{array}{c}\text { Tomava anador quando dava febre. [...] Tomava chá de mastruz com leite. Não } \\
\text { gosto de ir para o hospital, eu fico nervoso. Nem sempre é bem atendido e tem } \\
\text { muita gente (E-8). }\end{array}$ \\
\hline & $\begin{array}{c}\text { Quase dez anos que eu tusso. [...] Tomava remédio de tosse por conta própria. Ia } \\
\frac{\text { na farmácia, tomava um remédio de tosse, tomava e melhorava. Passei anos }}{\text { assim. [...] (E-4). }}\end{array}$ \\
\hline & $\begin{array}{c}\text { Eu tomo remédio em casa mesmo. Quando eu estou sentindo uma dor eu peço } \\
\text { informação para alguém mais visado. Já tomei chá. [...] }\end{array}$ \\
\hline & $\begin{array}{c}\text { Primeiro eu tomei remédio em casa, porque estava com dor de cabeça, até que eu } \\
\text { não aguentei mais. [...] Eu passei um mês em casa doente... Pensava que não era } \\
\text { nada grave }[\ldots](E-9) .\end{array}$ \\
\hline
\end{tabular}

\section{Formação Discursiva I: A relação dos sentimentos dos sujeitos com o adoecimento por TB e as estratégias de enfrentamento utilizadas}

É possível identificar na sequência dos discursos contidos nos fragmentos, sentimentos relacionados à morte, na relação posta entre o adoecer por TB e o morrer. Encontram-se presentes tanto a expectativa da morte física, como também a morte social, determinada pela ideia de desprezo e rejeição. O sentimento de medo é comum em ambas as situações. No caso do E-5, salienta-se a condição de produção imediata, em que ela encontrava-se em extrema desnutrição e no ápice do agravamento da doença.

Nestas sequencias discursivas (SD), evidenciam-se os sentimentos que integram a memória discursiva e caracterizam o imaginário da doença, evidente no processo parafrástico em que se mantém o mesmo dizer sedimentado e cristalizado de que adoecer de TB significa morrer ou isolar-se, este último decorrente da falta de conhecimento e do estigma. Entretanto, em tons mais esmaecidos, porém em menor proporção, observa-se em outros discursos a incorporação do conhecimento sobre a cura da doença, o que corrobora para enfraquecer o discurso centrado na ideia de morte e evocativo de estigma e preconceito, a exemplo:

Eu não senti muita coisa não, porque sempre ouvia falar que tinha cura, disseram que era só fazer o tratamento que tinha cura (E-3).

No imaginário coletivo, o temor e a aversão ante a doença justificavam-se pelo desconhecimento de suas causas e pela ineficácia do seu tratamento e associação do doente com comportamento desviante referente às normas sociais. "O horror diante da tuberculose acaba por fazer dela um tabu, um objeto de interdição e seu sintoma extremo é a estigmatização do doente e seu consequente isolamento"(14). Retomando o fragmento discursivo do primeiro quadro, observa-se que uma possível estratégia de enfrentar a doença seria o suicídio. Assim, se pensa em virtude do indício fazer besteira, pertencente a E-7.

$\mathrm{Na}$ Noruega, uma pesquisa sobre as causas do retardo do diagnóstico da TB apontou dentre as razões relacionadas aos pacientes o estigma produzido no adoecer por $\mathrm{TB}^{(15)}$. Em muitos países, devido às características culturais, as dificuldades enfrentadas pelos doentes são agravadas pelo estigma social da doença, influenciando a procura por cuidados profissionais, a adesão ao tratamento e até favorecendo o abandono do mesmo $^{(15)}$.

Em relação às estratégias utilizadas pelo portador de TB, frente à evidência do agravo, no Quadro 2 estão as $\mathrm{SD}$, nas quais os sujeitos relataram como primeira intervenção a automedicação, a qual se apresenta como uma prática cultural e que produz sentidos advindos da cultura milenar de autocuidar-se, principalmente pelo uso de remédios caseiros e, que nos tempos atuais, reforça a concepção biomédica, centrada na medicação alopática, sem a anuência de um profissional habilitado. São identificados traços comportamentais, culturais e sociais que mostram a forma peculiar como os sujeitos adoecidos de TB de uma determinada localidade, interpretam a descoberta da doença e a forma primeira de enfrentá-la.

A prática irracional da automedicação eleva o risco de eventos adversos e de mascaramento de doenças, o que pode favorecer o retardo do diagnóstico ${ }^{(16)}$. No que concerne à prática da automedicação pelos portadores de $\mathrm{TB}$, geralmente ocorre o mascaramento da doença com consequente agravamento dos sintomas, atraso do diagnóstico e a perpetuação da cadeia de transmissão.

A automedicação produz sentidos provenientes das formações ideológicas dos sujeitos que a praticam. As práticas de automedicação expressam a crescente medicalização e farmacologização das sociedades modernas, que se traduz na ideologia biomédica. Paralelamente, a padronização da sua prescrição favoreceu uma gradual apropriação leiga dos critérios de 
decisão médica, que é reproduzida nas soluções leigas para os problemas mais comuns de saúde ${ }^{(17)}$.

Em um estudo sobre o retardo do diagnóstico da TB, realizado na Etiópia, observou-se uma associação significativa entre a automedicação e o atraso do diagnóstico, em que $61,7 \%$ dos entrevistados buscaram inicialmente serviços informais de saúde, tais como os curandeiros tradicionais $(27,1 \%)$ e as farmácias $(31 \%)^{(4)}$. Outra pesquisa, realizada no país de Gana, detectou que nos estágios iniciais da doença, a maioria dos pacientes não reconhecem os seus sinais e sintomas como característicos da TB, recorrendo ao uso de medicamentos para tosse comum(18).

Em síntese, no enfrentamento da TB, evidenciam-se estratégias, saídas, que acentuam o desconhecimento e a extensão do conceito de medicalização da saúde, no caso, revestida de traços culturais, atualizada pelo acesso fácil a fármacos e consumidos segundo a máxima "de médico e louco, todo mundo tem um pouco". Na perspectiva do interdiscurso, se misturam a tradição e a atualização do agir em função de resolver o problema. Sem dúvida, nesse caso, a automedicação influencia para o atraso do diagnóstico, uma vez que antes da procura pelo serviço de saúde se recorre a esta estratégia.

\section{Formação Discursiva II: A busca pelo serviço de saúde oficial mediada pelo agravamento da sintomatologia}

Sobre o que tenha sido determinante para que os sujeitos procurassem o serviço de saúde, eles relataram a busca por assistência no momento que perceberam o agravamento dos sintomas. Como consequência da busca tardia ao serviço de saúde, seis dos entrevistados vivenciaram a internação hospitalar. Dentre os sintomas percebidos, foram descritos a hemoptise, cansaço extremo, vômitos, febre incessante e dor torácica, como revelados nos fragmentos discursivos do Quadro 3.

Quadro 3: Interpretação dos sinais e sintomas da doença que motivaram a busca do serviço de saúde. Cabedelo, PB, Brasil, 2011.

\begin{tabular}{|c|c|}
\hline Sequências discursivas & Fragmentos Discursivos \\
\hline $\begin{array}{c}\text { Cansaço, dificuldade para } \\
\text { andar. }\end{array}$ & \multirow{2}{*}{$\begin{array}{c}\text { Eu senti que era grave, comecei a cansar muito, não conseguia nem andar. Porque era de } \\
\text { noite, de madrugada quando eu fui, porque cansei muito. Demorei dois meses para procurar o } \\
\text { hospital }[\ldots](E-7) .\end{array}$} \\
\hline $\begin{array}{l}\text { Demora de } 2 \text { meses para } \\
\text { buscar o serviço de } \\
\text { saúde. }\end{array}$ & \\
\hline Hemoptise. & \multirow{2}{*}{$\begin{array}{c}\text { Porque eu vi sangue, quando eu cuspi veio com sangue na saliva. Aí minha menina disse para } \\
\text { eu procurar o médico e me levou pro Clementino. Lá disseram que eu ia ficar internada três } \\
\text { dias, mas eu fiquei dezenove dias [...] Eu tinha muito medo de me internar [...] era por causa } \\
\text { disso, eu tinha medo de descobrir e ficar internada [...] (E-4). }\end{array}$} \\
\hline $\begin{array}{l}\text { Busca imediata pelo } \\
\text { serviço de saúde. }\end{array}$ & \\
\hline $\begin{array}{l}\text { Percepção inicial de } \\
\text { sintomas comuns de um } \\
\text { resfriado. }\end{array}$ & Eu passei um mês em casa doente... Pensava que não era nada grave $[\ldots]$ (E-9). \\
\hline $\begin{array}{l}\text { Procura pelo serviço de } \\
\text { saúde mediante a } \\
\text { gravidade dos sintomas. }\end{array}$ & $\begin{array}{l}\text { [...] Só fui ao hospital quando comecei a vomitar mesmo. Pensei que era febre normal. } \\
\text { Quando começou a me prejudicar mais, foi quando eu procurei o médico [...] (E-3). }\end{array}$ \\
\hline
\end{tabular}

$O$ sentimento medo adstrito à $\mathrm{TB}$, revela-se não como um atributo da doença, mas pela condição de reclusão hospitalar, a qual, potencialmente, a presença da doença irá ocasionar. O medo, do ponto de vista indiciário, é realmente um dos elementos relacionados ao atraso do diagnóstico da TB.

Nota-se também que os sintomas da doença são interpretados como não graves e associados a doenças respiratórias, principalmente resfriado, fato que também concorre para a procura tardia do serviço de saúde. Mais uma vez se observa que o traço cultural é determinante na configuração do processo saúde-doença-cuidado. Nesse sentido, a gravidade do quadro é o principal elemento que influencia a busca pelo serviço de saúde. Até então, o sujeito, pode-se dizer, é o médico de si mesmo, o cuidado pertence ao próprio sujeito adoecido e a sua família. Na opacidade do discurso, é também o medo, revelado pela gravidade dos sintomas, que leva o doente a buscar o serviço de saúde, a ajuda de profissionais.

Os discursos revelam que ao buscar o serviço de saúde, surgem outros aspectos que contribuem para o retardo do diagnóstico, destacando-se a ausência de capacitação dos profissionais no diagnóstico e suspeição da TB e a falta de resolutividade dos serviços da Atenção Primária à Saúde (APS), como se observam nas seguintes SD:

[...] eu tossia muito, aquela tosse seca, rodei muito pelos PSFs, ia ao médico, o médico dizia que era tosse alérgica e passava um xarope e não melhorava. Fui para vários médicos, fui até para o PSF aqui; no pronto-socorro tirei 
a chapa e disse que eu não tinha nada e cada vez piorando. [...] Fui para médica da alergia e ela disse que pela minha idade não era alergia e disse para eu tirar a chapa de pulmão, foi quando eu fui tirar a chapa na clínica. Eu vim ter conhecimento de tudo no [SERVIÇO DE SAÚDE] particular (E-2).

[...] Eu não confio no PSF mais, só se for uma coisa muito simples, se eu ver que é uma coisa mais séria eu corro para o particular (E-2).

Percebe-se que a partir do momento que o sujeito com TB não consegue resolver o problema da doença, ele deixa de ter o controle sobre o cuidado de si e recorre ao cuidado oficial. No entanto, a não resolutividade deste serviço frente à necessidade do doente, resulta no atraso do diagnóstico. Ainda, ressalta-se o sentimento de desconfiança gerado com consequente quebra de vínculo desses usuários de saúde em relação à unidade de saúde local, a vulnerabilidade social dos mesmos e a despesa com a saúde no serviço particular.

Desde o ano de 2003, a OMS vem demonstrando sua preocupação em relação à qualificação das equipes de saúde, para assumirem as responsabilidades com as ações de controle da TB, questão que emerge no bojo da descentralização e integração do controle da doença nos serviços de APS e que representa um dos desafios para a expansão sustentável da estratégia DOTS e para o alcance das metas de detecção e cura ${ }^{(19)}$.

De acordo com uma pesquisa realizada na Noruega, dentre os fatores que causam o retardo do diagnóstico da $T B$, identificou-se que a principal causa do atraso relacionado aos serviços de saúde consistiu na falha de diagnóstico preciso na apresentação inicial da doença, apesar dos sintomas característicos ${ }^{(15)}$.

\section{Formação Discursiva III: Os sentimentos dos sujeitos frente ao tratamento e a busca de cuidados complementares}

Quanto às perspectivas referentes ao tratamento, os doentes descreveram os sentimentos gerados no momento em que explicaram sobre a terapêutica, a sensação de "estranheza" ante o tempo que seria destinado ao tratamento e as reações adversas dos medicamentos (Quadro 4).

Quadro 4: Atitudes e sentimentos frente ao tratamento da doença. Cabedelo, PB, Brasil. 2011.

\begin{tabular}{|c|c|}
\hline $\begin{array}{l}\text { Sequências } \\
\text { discursivas }\end{array}$ & Fragmentos Discursivos \\
\hline \multirow{2}{*}{$\begin{array}{l}\text { A longa duração do } \\
\text { tratamento. }\end{array}$} & $\begin{array}{c}\text { Eu pensei: vai ser muito tempo o tratamento! Para mim é uma eternidade seis meses. Para mim, } \\
\text { era para ser só três meses, dois meses, para terminar logo, para ficar logo boa (E-4). }\end{array}$ \\
\hline & {$[\ldots]$ Estranhei que era muito tempo para tomar os medicamentos $(E-7)$.} \\
\hline \multirow{2}{*}{$\begin{array}{l}\text { Melhora devido ao } \\
\text { tratamento e à } \\
\text { mudança de hábitos. }\end{array}$} & $\begin{array}{c}\text { Graças a Deus! Acho que o que está ajudando a melhorar é meu esforço, eu não saio para lugar } \\
\text { nenhum, sou preocupado com o horário do medicamento [...] (E-2). }\end{array}$ \\
\hline & $\begin{array}{l}\text { [...] Os remédios me ajudaram a melhorar e muito repouso que tive [...] Agora eu sei o que fazer } \\
\text { para não ter mais isso: diminuir o cigarro, não levar chuva direto, não levar muita poeira (E-3). }\end{array}$ \\
\hline $\begin{array}{c}\text { Reações adversas e } \\
\text { fragilidades na } \\
\text { adesão ao } \\
\text { tratamento. }\end{array}$ & $\begin{array}{l}\text { E logo no começo quando comecei a tomar passei mal, agonia e meu coração muito alterado, até } \\
\text { quando tomo ainda me sinto mal. Quando eu tomo, com pouquinho tempo vomito (E-7). }\end{array}$ \\
\hline \multirow{2}{*}{$\begin{array}{c}\text { Reações adversas e o } \\
\text { abandono do } \\
\text { tratamento. }\end{array}$} & $\begin{array}{l}\text { [...] Eu pensei em sair do hospital, em parar os medicamentos pela dor nos ossos. [...]. Pensei em } \\
\text { parar, mas minha menina disse que se eu parasse ia me prejudicar, e lá no hospital disseram que } \\
\text { se ficasse um dia sem tomar voltava tudo de novo, disseram que volta mais forte (E-4). }\end{array}$ \\
\hline & $\begin{array}{c}\text { [...] Eu já pensei em parar, porque eu estou sentindo que eu estou ficando mais fraca ainda e cada } \\
\text { dia que eu tomo o remédio eu estou ficando mais magra. [...]. Eu me senti melhor, comecei a } \\
\text { tomar e depois parei. [...] Quando completou os seis meses eu parei e era para eu ter voltado lá } \\
\text { para revisão e eu não me interessei. Aí depois eu não liguei e quando vim morar aqui na casa da } \\
\text { minha mãe começou tudo de novo. [...] Eu pensei: com seis meses eu estou boa, para que eu ir } \\
\text { de novo? (E-5). }\end{array}$ \\
\hline $\begin{array}{l}\text { Percepção precoce de } \\
\text { cura e abandono da } \\
\text { terapêutica. }\end{array}$ & $\begin{array}{c}\text { Eu parei, desisti, fiquei um mês sem tomar quando faltavam dois meses para terminar. Eu não } \\
\text { sentia nada, não tava cansando, aí deu a recaída e foi pior, fui pro Clementino. Desgosto, não falei } \\
\text { para ninguém (E-7). }\end{array}$ \\
\hline
\end{tabular}

Nestes fragmentos discursivos, nota-se que as reações adversas aos medicamentos, o tempo prolongado da terapêutica e a percepção precoce de cura fragilizaram a adesão ao tratamento e favoreceram atitudes de predisposição ao abandono da terapêutica.

Diversos estudos sobre os fatores associados ao abandono do tratamento da TB têm sido realizados no
Brasil, devido à importância da adesão terapêutica para o sucesso do tratamento e para o controle da doença. Dentre as causas do abandono, foram identificados os seguintes aspectos: ser do sexo masculino; tabagismo, etilismo e uso de drogas ilícitas; história de internação prévia(20-21); informações deficitárias sobre a doença; intolerância medicamentosa; interrupção do tratamento 
decorrente da regressão dos sintomas; tempo prolongado de tratamento e a grande quantidade de comprimidos ingeridos $^{(22-23)}$.

No que concerne à busca por alternativas complementares de cuidado, observa-se nos fragmentos discursivos subsequentes, o predomínio do discurso religioso e da crença no divino para obter a cura.

Às vezes eu ia para Igreja Universal para ver se eu ficava boa. Mas o povo diz que só quem fica boa é quem tem fé [...]. Eu acho que estou melhorando [...]. Eu estou achando que são os comprimidos mesmo, e a comida, porque antigamente eu não comia e agora eu estou comendo direitinho. Para mim Deus me ajudou demais (E4).

Eu acho que estou melhorando demais. [...] se não fosse Deus eu estava morta mesmo. Primeiro Jesus, depois os remédios, se não fosse Jesus eu já estava no outro mundo (E-9).

Da ajuda de Deus e eu indo para igreja eu acho que eu estou melhorando, mas dos remédios não. Porque quanto mais que eu tomo, eu estou ficando mais magra ainda. $O$ povo que me conhece diz que eu estou ficando pior do que eu já era. Eu escuto a palavra de Deus, e eu não tusso mais como eu tossia muito. Minha mãe está me ajudando também. Eu estou tomando os remédios só por tomar mesmo (E-5).

Percebe-se que nos dois primeiros discursos, há uma dualidade de concepções de cura que se desvela na adesão ao tratamento e na espiritualidade dos sujeitos. No terceiro discurso, o agravamento da doença de E-5 provocou a descrença no esquema terapêutico e a esperança de melhora focalizou-se na ação divina.

A concepção de saúde baseada na religião permanece enraizada na memória discursiva de muitos indivíduos e continua produzindo os mesmos efeitos de sentidos observados há milênios, quando prevalecia a concepção mágico-religiosa ou ontológica, segundo a qual a doença decorre da ação de forças sobrenaturais e cura está condicionada à vontade divina ou a rituais $\operatorname{sagrados}^{(7)}$.

Esta dualidade de concepções revela sentimentos associados ao mundo da medicina oficial e ao mundo cultural, sobretudo religioso, uma vez que o sujeito, mesmo em tratamento, também cuida de si, demonstrando como o seu mundo cultural é determinante. Desta forma, o serviço de saúde que não considera os sentimentos diretamente associados ao cuidado, concorre para o retardo do diagnóstico e fragiliza a adesão à terapêutica.
Portanto, ressalta-se a necessidade de organização dos serviços na perspectiva da integralidade, que tem em suas concepções a ideia-força de considerar o usuário como sujeito a ser atendido e respeitado em suas demandas e necessidades ${ }^{(24)}$. A produção de cuidados de saúde e de enfermagem deve valorizar a subjetividade e a individualidade de cada sujeito, buscando conhecer as concepções dos indivíduos sobre o seu processo saúdedoença, o que se constitui como eixo central na busca pela redução de danos e de vulnerabilidade social, objetivando o êxito do processo terapêutico e o alcance de melhores níveis de qualidade de vida para os usuários dos serviços de saúde ${ }^{(25)}$.

\section{CONCLUSÃO}

Os aspectos culturais, comportamentais e sociais dos sujeitos com TB influenciaram sobremaneira o retardo do diagnóstico e a adesão ao tratamento. A prática cultural da automedicação, identificada como primeira estratégia de enfrentamento utilizada pelo doente de TB, contribuiu para a busca tardia do serviço de saúde e consequente retardo do diagnóstico e agravamento dos casos. Por conseguinte, a percepção da gravidade da doença foi determinante para a busca do serviço de saúde. Entretanto, o sentimento de medo do sujeito adoecido por TB relacionado à possibilidade de internação hospitalar favoreceu também o atraso do diagnóstico.

Ressalta-se ainda que o estigma associado à doença influenciou a busca tardia por cuidados profissionais e a adesão ao tratamento. Outro aspecto relevante que favoreceu o retardo do diagnóstico foi a falta de confiança no serviço de saúde devido à deficiência dos profissionais para suspeição e diagnóstico da doença.

Em relação aos comportamentos dos portadores de TB frente à terapêutica oficial, observou-se que as reações adversas aos medicamentos, o tempo prolongado da terapêutica e a percepção precoce de cura fragilizaram a adesão ao tratamento, predispondo-os ao abandono do mesmo. Assim, reitera-se a relevância da integralidade e da intersetorialidade na atenção aos sujeitos com TB, considerando as peculiaridades do contexto socioeconômico e cultural dos indivíduos, assim como os sentimentos implicados na vivência do adoecimento e que interferem diretamente na busca do serviço de saúde e na adesão ao tratamento.

Dessa forma, salienta-se a necessidade de construção de relações de vínculo entre os sujeitos com TB e os profissionais de saúde, sustentada por uma abordagem dialógica que permita conhecer as particularidades e os sentimentos que determinam o enfrentamento da doença 
e por conseguinte garantam a longitudinalidade da atenção e a adesão à terapêutica.

Sugere-se ainda, que as práticas de atenção à pessoa acometida por TB sejam redirecionadas para a educação

\section{REFERÊNCIAS}

1. Santos MLSG, Vendramini SHF, Gazetta CE, Oliveira SAC, Villa TCS. Pobreza: caracterização socioeconômica da tuberculose. Rev. Latino-Am. Enfermagem. 2007;15(spe):762-67. 2. World Health Organization. Global Tuberculosis Control. WHO Report; Geneva: World Health Organization; 2013.

3. Díez M, Bleda MJ, Alcaide J, Castells C, Cardenal JI, Domínguez $A$, et al. Determinants of health system delay among confirmed tuberculosis cases in Spain. Eur J Public Health. [Internet]. 2005 [acesso em: 25 ago 2010] 15(4):343-9. Disponível em: http://www.ncbi.nlm.nih.gov/pubmed/16014664. 4. Yimer S, Bjune G, Alene G. Diagnostic and treatment delay among pulmonary tuberculosis patients in Ethiopia: a cross sectional study. BMC Infec Dis. 2005;5:112.

5. Orlandi EP. Análise de discurso: princípios e procedimentos. $8^{a}$ ed. Campinas: Pontes; 2009, 100p.

6. Polak YNS, Kalegari DRG, Domingues DE, Yamasaki IS. A Compreensão de doença dos adultos da grande Curitiba. Cogitare enferm. 1996;1(2):11-8.

7. Scliar M. História do Conceito de Saúde. Physis [Internet]. 2007 [acesso em: 17 jun 2012];17(1):29-

41. Disponível em: http://www.scielo.br/pdf/physis/v17n1/v17n1a03.pdf. 8. Gazzinelli MF, Gazzinelli A, Reis DC, Penna CMM. Educação em saúde: conhecimentos, representações sociais e experiências da doença. Cad. Saúde Pública [Internet]. 2005 [acesso em: 17 jun 2014]; 21(1):200-6. Disponível em:

http://www.scielo.br/pdf/csp/v21n1/22.pdf.

9. Freitas IM, Crispim JA, Pinto IC, Villa TCS, Brunello MEF, Pinto PFPS et al. Knowledge and perception about tuberculosis of patients' families under directly observed treatment at a health service in Ribeirão Preto-SP, Brazil. Texto Contexto Enferm. [Internet]. 2012 [acesso em: 17 jun 2014];21(3):6429. Disponível em:

http://www.scielo.br/pdf/tce/v21n3/en_v21n3a20.pdf. 10. Sinan [Internet]. Tuberculose - casos confirmados notificados no Sistema de Informação de Agravos de Notificação. 2014. [acesso em: 17 jun 2014]. Disponível em:

http://dtr2004.saude.gov.br/sinanweb/tabnet/dh?sinannet/tuber culose/bases/tubercbrnet.

11. Minayo MCS. O desafio do conhecimento: pesquisa qualitativa em saúde. 11 ed. São Paulo: Hucitec; 2008. 12. Instituto Brasileiro de Geografia e Estatística [Internet]. Brasília: Ministério do Planejamento, Orçamento e Gestão; 2010 [acesso em: 20 jan 2011]. Censo demográfico de Cabedelo. Disponível em:

http://www.ibge.gov.br/cidadesat/topwindow.htm?1.

13. Wang W, Jing Q, Abdullah ASM, Xu B. Barriers in accessing to tuberculosis care among non-residents in Shanghai: a descriptive study of delays in diagnosis. Eur J Public Health. [Internet]. 2007 [acesso em: 27 out 2011];17(5):419-23. Disponível em: http://www.ncbi.nlm.nih.gov/pubmed/17412714

14. Pôrto A. Representações sociais da tuberculose: estigma e preconceito. Rev. Saúde Públ. [Internet]. 2007 [acesso em: 28nov 2010];41 Suppl 1:43-9. Disponível em: http://www.scielo.br/pdf/rsp/v41s1/6493.pdf

15. Farah MG, Rygh JH, Steen TW, Selmer R, Heldal E, Bjune G. Patient and health care system delays in the start of tuberculosis treatment in Norway. BMC Infect Dis. 2006;6.

16. Schmid B, Bernal R, Silva NN. Automedicação em adultos de baixa renda no município de São Paulo. Rev. Saúde Públ. [Internet]. 2010 [acesso em: 17 jun 2014]; 44(6):103945. Disponível em: http://www.scielo.br/pdf/rsp/v44n6/1493.pdf. em saúde, considerando as singularidades dos usuários e peculiaridades das diferentes realidades sociais.

17. Lopes NM. Automedicação: algumas reflexões sociológicas. Sociologia, problemas e práticas. [Internet]. 2001 [acesso em: 29 out 2011$]$; 37:141-65. Disponível em:

http://www.scielo.oces.mctes.pt/pdf/spp/n37/n37a07.

18. Dodor EA. The feelings and experiences of patients with tuberculosis in the Sekondi-Takoradi Metropolitan District: implications for TB control efforts. Ghana Med J. 2012 [acesso em: 09 jun 2014];46(4):211-18. Disponível em: http://www.ncbi.nlm.nih.gov/pmc/articles/PMC3645176/?tool=p ubmed.

19. Monroe AA, Gonzales, RIC, Palha PF, Sassaki CM, Ruffino Netto A, Vendramini SHF, et al. Envolvimento das equipes de atenção básica à saúde no contexto da tuberculose. Rev Esc Enferm USP. 2008;42(2):262-67.

20. Ribeiro AS, Amado VM, Camalier AA, Fernandes MMA, Schenkman S. Estudo caso-controle de indicadores de abandono em doentes com tuberculose. J. bras. pneumol. 2000;26(6):29196.

21. Lima MBD, Mello DA, Morais APP, Silva WCD. (2001). Estudo de casos sobre abandono do tratamento da tuberculose: avaliação do atendimento, percepção e conhecimentos sobre a doença na perspectiva dos clientes (Fortaleza, Ceará, Brasil). Cad. Saúde Pública. 2001;17(4):877-85.

22. Sá LD, Souza KMJ, Nunes MG, Palha, PF, Nogueira JA, Villa TCS. Tratamento da tuberculose em unidades de saúde da família: histórias de abandono. Texto Contexto Enferm. [Internet]. 2007 [acesso em: 29 abr 2011];16(4):712-18. Disponível em:

http://www.scielo.br/pdf/tce/v16n4/a16v16n4.pdf.

23. Alves RS, Souza KMJ, Oliveira AAV, Palha PF, Nogueira JA, Sá LD. (2012). Abandono do tratamento da tuberculose e integralidade da atenção na estratégia saúde da família. Texto Contexto Enferm. [Internet].2012 [acesso em: 17 jun 2014];21(3):650-7. Disponível em:

http://www.scielo.br/pdf/tce/v21n3/v21n3a21.pdf.

24. Pinheiro R. Práticas de saúde e integralidade: as experiências inovadoras na incorporação e desenvolvimento de novas tecnologias assistenciais de atenção aos usuários no SUS. In: Brasil. Ministério da Saúde. Secretaria de Gestão de Investimentos em Saúde. Projeto Reforsus Componente II. Experiências Inovadoras no SUS: relatos de experiências: novas tecnologias assistenciais: Secretarias Estaduais e Municipais de Saúde. Brasília (Brasil): Ministério da Saúde; 2002. p. 15. 25. Farias SNP, Medeiros CRS, Paz EPA, Lobo AJS, Ghelman LG. Integralidade no cuidado: estudo da qualidade de vida dos usuários com tuberculose. Esc. Anna Nery [Internet]. 2013 [acesso em: 09 jun 2014];17(4):749-54. Disponível em: http://www.scielo.br/pdf/ean/v17n4/1414-8145-ean-17-040749.pdf.

Artigo recebido em 07/06/2013.

Aprovado para publicação em 05/06/2014. Artigo publicado em 31/03/2015. 